\title{
High thermoelectric performance of oxyselenides: intrinsically low thermal conductivity of Ca-doped BiCuSeO
}

\author{
Yan-Ling Pei ${ }^{1}$, Jiaqing $\mathrm{He}^{2}$, Jing-Feng $\mathrm{Li}^{3}, \mathrm{Fu} \mathrm{Li}^{3}$, Qijun Liu ${ }^{4,5}$, Wei Pan ${ }^{3}$, Celine Barreteau ${ }^{6}$, David Berardan ${ }^{6}$, \\ Nita Dragoe ${ }^{6}$ and Li-Dong Zhao ${ }^{6}$
}

We report on the high thermoelectric performance of p-type polycrystalline $\mathrm{BiCuSeO}$, a layered oxyselenide composed of alternating conductive $\left(\mathrm{Cu}_{2} \mathrm{Se}_{2}\right)^{2-}$ and insulating $\left(\mathrm{Bi}_{2} \mathrm{O}_{2}\right)^{2+}$ layers. The electrical transport properties of $\mathrm{BiCuSeO}$ materials can be significantly improved by substituting $\mathrm{Bi}^{3+}$ with $\mathrm{Ca}^{2}{ }^{2}$. The resulting materials exhibit a large positive Seebeck coefficient of $\sim+330 \mu \mathrm{VK}^{-1}$ at $300 \mathrm{~K}$, which may be due to the 'natural superlattice' layered structure and the moderate effective mass suggested by both electronic density of states and carrier concentration calculations. After doping with $\mathrm{Ca}$, enhanced electrical conductivity coupled with a moderate Seebeck coefficient leads to a power factor of $\sim 4.74 \mu \mathrm{W} \mathrm{cm}{ }^{-1} \mathrm{~K}^{-2}$ at $923 \mathrm{~K}$. Moreover, BiCuSeO shows very low thermal conductivity in the temperature range of $300\left(\sim 0.9 \mathrm{~W} \mathrm{~m}^{-1} \mathrm{~K}^{-1}\right)$ to $923 \mathrm{~K}\left(\sim 0.45 \mathrm{~W} \mathrm{~m}^{-1} \mathrm{~K}^{-1}\right)$. Such low thermal conductivity values are most likely a result of the weak chemical bonds (Young's modulus, $E \sim 76.5 \mathrm{GPa}$ ) and the strong anharmonicity of the bonding arrangement (Gruneisen parameter, $\gamma \sim 1.5$ ). In addition to increasing the power factor, Ca doping reduces the thermal conductivity of the lattice, as confirmed by both experimental results and Callaway model calculations. The combination of optimized power factor and intrinsically low thermal conductivity results in a high $Z T$ of $\sim 0.9$ at $923 \mathrm{~K}$ for $\mathrm{Bi}_{0.925} \mathrm{Ca}_{0.075} \mathrm{CuSeO}$.

NPG Asia Materials (2013) 5, e47; doi:10.1038/am.2013.15; published online 17 May 2013

Keywords: BiCuSeO; electrical conductivity; Seebeck coefficient; thermal conductivity; thermoelectric

\section{INTRODUCTION}

As thermoelectric materials are capable of creating electricity from waste heat, they are relevant to sustainable energy solutions and thus receive a significant amount of scientific attention. The efficiency of thermoelectric devices is determined by a dimensionless figure of merit $(Z T)$, which is defined as $Z T=\left(S^{2} \sigma / \kappa\right) T$, where $S, \sigma, \kappa$, and $T$ are the Seebeck coefficient (thermopower), electrical conductivity, thermal conductivity and absolute temperature, respectively. ${ }^{1}$ Efforts to enhance the $Z T$ involve either increasing the power factor $\left(S^{2} \sigma\right)$ or decreasing the thermal conductivity $(\kappa) .^{2}$ Examples of these efforts include modifying the band structure by creating electronic resonance states, ${ }^{3}$ designing quantum confinement effects, ${ }^{4}$ and using electron energy barrier filtering ${ }^{5}$ to increase the Seebeck coefficient; synthesizing parent nanocrystalline materials, ${ }^{6}$ in situ forming nanoscale dots, ${ }^{7}$ precipitating nano-phases, ${ }^{8}$ and artificially introducing nano-particles ${ }^{9}$ to reduce the lattice thermal conductivity. Alternatively, high-performance single-phase thermoelectric materials can be obtained using materials with intrinsically low lattice thermal conductivities. Typical materials included in this class are as follows: $\mathrm{AgSbTe}_{2}\left(\kappa \sim 0.39 \mathrm{Wm}^{-1} \mathrm{~K}^{-1}\right.$, $Z T \sim 1.6$ at $673 \mathrm{~K}),{ }^{10,11} \mathrm{Ag}_{9} \mathrm{TlTe}_{5}\left(\kappa \sim 0.22 \mathrm{Wm}^{-1} \mathrm{~K}^{-1}, Z T \sim 1.2\right.$ at $700 \mathrm{~K}),{ }^{12} \mathrm{Ag}_{0.95} \mathrm{GaTe}_{2}\left(\kappa \sim 0.20 \mathrm{Wm}^{-1} \mathrm{~K}^{-1}, \quad Z T \sim 0.7\right.$ at $\left.850 \mathrm{~K}\right),{ }^{13}$ $\mathrm{Ag}_{3.9} \mathrm{Mog}_{9} \mathrm{Se}_{11}\left(\kappa \sim 0.75 \mathrm{Wm}^{-1} \mathrm{~K}^{-1}, Z T \sim 0.6\right.$ at $\left.800 \mathrm{~K}\right),{ }^{14} \mathrm{Cu}_{3} \mathrm{SbSe}_{4}$ $\left(\kappa \sim 0.50 \mathrm{Wm}^{-1} \mathrm{~K}^{-1}, \quad Z T \sim 0.8\right.$ at $\left.650 \mathrm{~K}\right),{ }^{15} \mathrm{Cu}_{2} \mathrm{Ga}_{4} \mathrm{Te}_{7} \quad(\kappa \sim 0.67$ $\mathrm{Wm}{ }^{-1} \mathrm{~K}^{-1}, Z T \sim 0.6$ at $\left.940 \mathrm{~K}\right),{ }^{16} \mathrm{Cu}_{2.1} \mathrm{Zn}_{0.9} \mathrm{SnSe}_{4}\left(\kappa \sim 0.50 \mathrm{Wm}^{-1}\right.$ $\mathrm{K}^{-1}, Z T \sim 0.9$ at $\left.860 \mathrm{~K}\right),{ }^{17} \mathrm{Cu}_{2} \mathrm{Ga}_{0.07} \mathrm{Ge}_{0.93} \mathrm{Se}_{3}\left(\kappa \sim 0.67 \mathrm{Wm}^{-1} \mathrm{~K}^{-1}\right.$, $Z T \sim 0.5$ at $745 \mathrm{~K}),{ }^{18} \mathrm{CsBi}_{4} \mathrm{Te}_{6}\left(\kappa \sim 0.50 \mathrm{Wm}^{-1} \mathrm{~K}^{-1}, Z T \sim 0.8\right.$ at $275 \mathrm{~K}),{ }^{19}$ and $\mathrm{K}_{2} \mathrm{Bi}_{8} \mathrm{Se}_{13}\left(\kappa \sim 0.80 \mathrm{Wm}^{-1} \mathrm{~K}^{-1}, Z T \sim 0.4\right.$ at $\left.400 \mathrm{~K}\right) .{ }^{20}$ Recently, we reported a quaternary $\mathrm{BiCuSeO}$ compound that exhibits very low thermal conductivity ${ }^{21-25}$ High $Z T$ values were achieved using this system by optimizing the electrical transport properties. Specifically, electrical conductivity was increased by $\mathrm{Sr}$ doping, introducing $\mathrm{Cu}$ deficiencies and Ba heavy metal doping. ${ }^{21-25}$

\footnotetext{
${ }^{1}$ School of Materials Science and Engineering, Beihang University, Beijing, China; ${ }^{2}$ Frontier Institute of Science and Technology (FIST), Xi'an Jiaotong University, Xi'an, China; ${ }^{3}$ State Key Laboratory of New Ceramics and Fine Processing, School of Materials Science and Engineering, Tsinghua University, Beijing, China; ${ }^{4}$ Institute of High Temperature and High Pressure Physics, School of Physical Science and Technology, Southwest Jiaotong University, Sichuan, China; 5 State Key Lab of Solidification Processing, School of Materials Science and Engineering, Northwestern Polytechnical University, Xi'an, China and ${ }^{6}$ LEMHE, ICMMO, University Paris-Sud and CNRS, Orsay, France Correspondence: Dr L-D Zhao, Department of Chemistry, Northwestern University, 2145 Sheridan Road, Evanston, IL 60208, USA.

E-mail: lidong-zhao@northwestern.edu

or Professor JQ He, Frontier Institute of Science and Technology (FIST), Xi'an Jiaotong University, Xi'an 710054, China

E-mail: he.jq@sustc.edu.cn
}

Received 2 November 2012; revised 25 February 2013; accepted 28 February 2013 
Although promising thermoelectric properties have been observed with $\mathrm{BiCuSeO}$ compounds, ${ }^{21-25}$ surprisingly little is known about their microstructure and the main cause of their low thermal conductivity. In this paper, we perform a systematic evaluation of the $\mathrm{BiCuSeO}$ system, including the structural, transport, optical and elastic properties, using a combination of electron microscopy observations and electronic structure calculations. Furthermore, $\mathrm{Ca}^{2+}$ is added as a hole dopant for the $\mathrm{Bi}^{3+}$ sites to improve the electrical transport properties $\left(S^{2} \sigma\right)$ and to reduce the lattice thermal conductivity by introducing point defects. A $Z T$ of $\sim 0.9$ is observed for a $\mathrm{Bi}_{0.925} \mathrm{Ca}_{0.075} \mathrm{CuSeO}$ sample at $923 \mathrm{~K}$. These results indicate that the $\mathrm{BiCuSeO}$ system should be investigated further for future applications in medium-temperature thermoelectric devices.

\section{EXPERIMENTAL PROCEDURES}

\section{Synthesis}

Samples with a chemical composition of $\mathrm{Bi}_{1-\mathrm{x}} \mathrm{Ca}_{\mathrm{x}} \mathrm{CuSeO}, \quad(x=0$, $0.025,0.05,0.075$, and 0.10 ) were synthesized using a two-step, solid-state reaction process. ${ }^{21-25}$ Stoichiometric mixtures of $\mathrm{Bi}_{2} \mathrm{O}_{3}$ $(3 \mathrm{~N}), \mathrm{Bi}(4 \mathrm{~N}), \mathrm{CaO}(3 \mathrm{~N}), \mathrm{Cu}(3 \mathrm{~N})$ and $\mathrm{Se}(5 \mathrm{~N})$ powders were thoroughly ground up by hand and then heated to $973 \mathrm{~K}$ for $12 \mathrm{~h}$ in a sealed evacuated quartz tube. The total sample mass was maintained at $\sim 10 \mathrm{~g}$; for example, when $x=0.075 \mathrm{Ca}, 3.8778 \mathrm{~g}$ of $\mathrm{Bi}_{2} \mathrm{O}_{3}, 2.1622 \mathrm{~g}$ of $\mathrm{Bi}, 0.1135 \mathrm{~g}$ of $\mathrm{CaO}, 1.7195 \mathrm{~g} \mathrm{Cu}$, and $2.1269 \mathrm{~g}$ of Se are used. Next, the powders were reground and then cold-pressed at a pressure of $250 \mathrm{MPa}$ using a $\Phi 13 \mathrm{~mm} \times 20 \mathrm{~mm}$ cylindrical mold. Finally, the cylinders were heated again to $993 \mathrm{~K}$ for $24 \mathrm{~h}$ in a sealed evacuated quartz tube. All sample preparation processes, including the weighing out of raw materials and grinding of powders, were performed in air.

\section{Electrical properties}

The electrical transport properties were examined using bar samples obtained by cutting along the longitudinal direction of the cylindrical samples discussed above. In this manner, $10 \times 3 \times 2 \mathrm{~mm}$ bars were obtained. These bars were used for the simultaneous measurement of the Seebeck coefficient as well as electrical conductivity using an Ulvac Riko ZEM-3 (Ulvac, Yohohama, Japan) instrument under a helium atmosphere in the temperature range of 300-923 K. Heating and cooling cycles generated reproducible electrical properties. In addition, the electrical properties of different slices obtained from the same ingot were similar, indicating that the samples exhibited a significant degree of homogeneity. Hall coefficients were measured using a home-built system with the four-contact Hall-bar geometry. The measurements were performed using both negative and positive polarities to eliminate Joule resistive errors using magnetic fields in the range of $0-1.25 \mathrm{~T}$.

\section{Thermal conductivity}

Thermal diffusivity measurements were performed on coins of $\varnothing$ $8 \mathrm{~mm}$ and a thickness of $\sim 2 \mathrm{~mm}$ prepared by cutting along the longitudinal direction of the cylinder. The samples were coated with a thin layer of graphite to minimize errors in determining the emissivity of the material. The thermal conductivity was calculated using the following equation: $\kappa=D \times C_{\mathrm{p}} \times \rho$, where the thermal diffusivity coefficient $D$ was measured using laser flash diffusivity on a Netzsch LFA457 (Netzsch, Selb, Germany) (wherein the heating and cooling cycles produced reproducible diffusivity measurements for a given sample); $C_{\mathrm{p}}$ is the specific heat capacity, which was indirectly derived using a standard sample (Pyroceram 9606) in the range of $300-923 \mathrm{~K}$; and the density $\rho$ of the sample was determined using sample dimension and mass and confirmed using gas pycnometer
(Micromeritics Accupyc1340, Norcross, GA, USA) measurements. All measured densities exhibit a value that is $\sim 90 \%$ of the theoretical density, $8.903 \mathrm{~g} \mathrm{~cm}^{-3}$, for BiCuSeO.

\section{Elastic properties}

The longitudinal and transverse acoustic velocities were measured using an ultrasonic instrument (Ultrasonic Pulser/Receiver Model 5900 PR, Panametrics, Waltham, MA, USA). The elastic constants and Poisson ratio were then calculated using the measured velocities. ${ }^{26}$

\section{Electron microscopy and X-ray diffraction}

Transmission electron microscopy (TEM) investigations were performed using a JEOL 2100F (JEOL, Tokyo, Japan) microscope operating at $200 \mathrm{kV}$. The TEM specimens were prepared by conventional standard methods. The procedures were performed including the cutting, grinding, dimpling, polishing and Ar-ion milling in a liquid nitrogen environment. For powder X-ray diffraction, samples were pulverized with an agate mortar and were then subjected to $\mathrm{Cu}$ $\mathrm{K}_{\alpha}(\lambda=1.5418 \AA)$ radiation in the reflection geometry using an Inel diffractometer equipped with a position-sensitive detector and operating at $40 \mathrm{kV}$ and $20 \mathrm{~mA}$.

\section{Electronic structure calculation}

CASTEP based on the plane-wave ultrasoft pseudopotential method was used to calculate the total energy. ${ }^{27}$ In this manner, the local density approximation (LDA) and the generalized gradient approximation (GGA) plus the Hubbard parameter (U) (Coulomb-interactioncorrected LDA and GGA) were calculated. The density-functional theory based on LDA suffers from a well-known gap problem, which is caused by the highly correlated nature of the system that leads to strong effective Coulomb interactions between the electrons. In this manner, the LDA may treat some states incorrectly, such as the d-states in materials containing three-dimensional transition metals, and especially when determining electron energy gap values. However, the plus Hubbard parameter (U) method has been shown to resolve this problem in compounds, ${ }^{28}$ such as $\mathrm{CuO}, \mathrm{CuAlO}_{2}$ and $\mathrm{CuAl}_{2} \mathrm{O}_{4}$, where the $\mathrm{U}$ is an on-site Coulomb repulsion parameter. The $\mathrm{Cu} 3 \mathrm{~d}^{10} 4 s^{1}$, Se $4 s^{2} 4 p^{4}$, Bi $6 s^{2} 6 p^{3}$ and $\mathrm{O} 2 s^{2} 2 p^{4}$ electrons are explicitly treated as valence electrons. In these calculations, a plane-wave cutoff energy of $450 \mathrm{eV}$, $6 \times 6 \times 3$ Monkhorst-Pack $k$ points as well as an energy conversion threshold of $5.0 \times 10^{-6} \mathrm{eV}$ per atom were used. ${ }^{29}$

\section{Band gap measurement}

The reflectance versus wavelength data were used to estimate the band gap by converting the reflectance measurement to an absorption value as described by the Kubelka-Munk equations: $\alpha / S=(1-R)^{2} / 2 R$, where $R$ is the reflectance, and $\alpha$ and $S$ are the absorption and scattering coefficients, respectively.

\section{RESULTS AND DISCUSSION}

\section{Structural and thermoelectric properties}

The crystal structure of $\mathrm{BiCuSeO}$ belongs to the $\mathrm{ZrSiCuAs}$-type structure with the tetragonal $\mathrm{P} 4 / \mathrm{nmm}$ space group that constitutes the $\left(\mathrm{Cu}_{2} \mathrm{Se}_{2}\right)^{2-}$ layers alternating with $\left(\mathrm{Bi}_{2} \mathrm{O}_{2}\right)^{2+}$ layers along the $c$-axis of the tetragonal cell, as shown in Figure 1a. ${ }^{30,31}$ Figure $1 \mathrm{~b}$ shows the typical samples used in this study, as well as the bar and coin that are used for electrical and thermal transport properties measurements, respectively. These materials were cut along the same longitudinal direction of the cylinder sample in case there is anisotropy in the layered crystal structure of $\mathrm{BiCuSeO}$, even though this material is polycrystalline. Figure 1c shows the powder X-ray diffraction patterns 
a

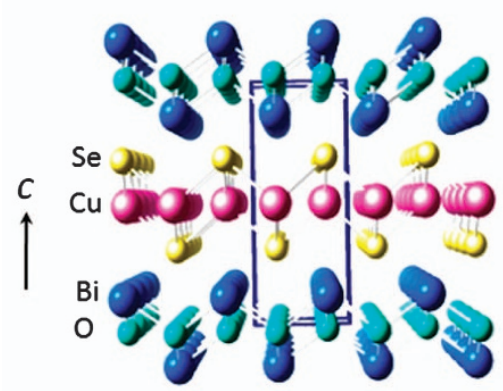

c

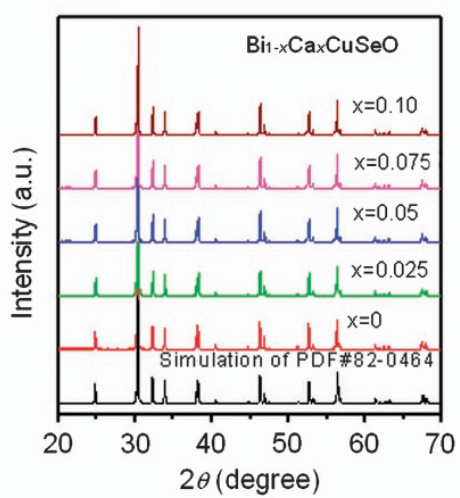

e

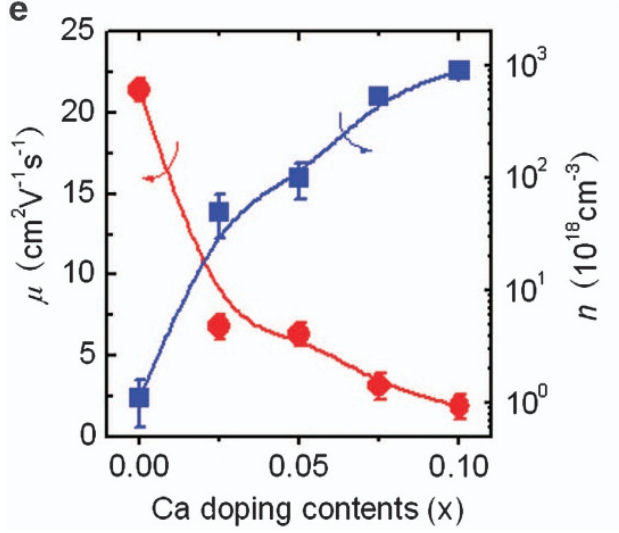

b

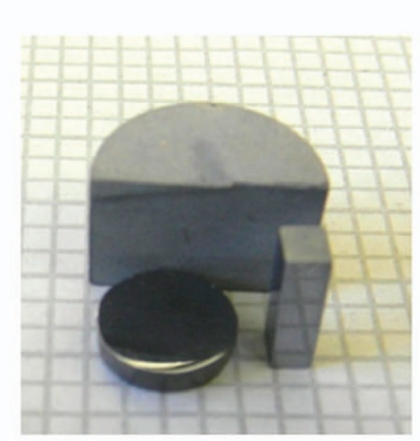

d
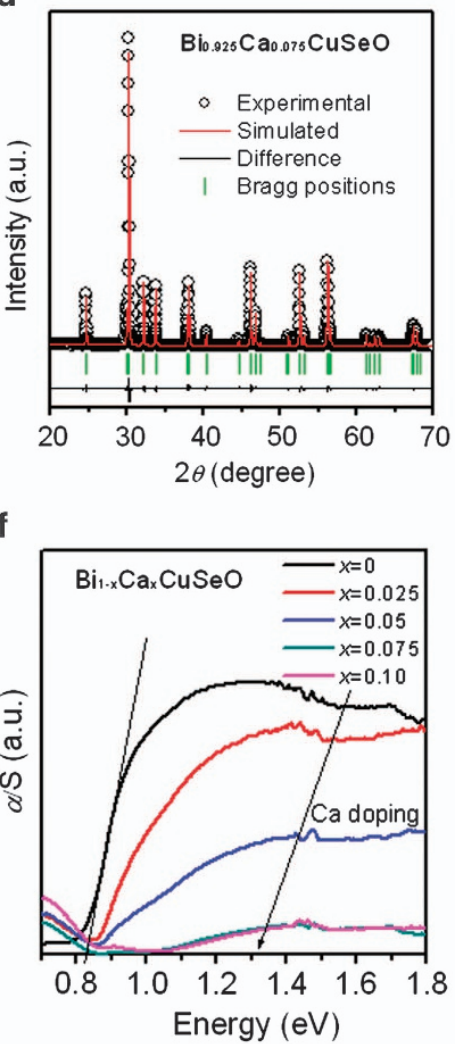

Figure 1 (a) The crystal structure of $\mathrm{BiCuSeO}$ as a ZrSiCuAs-type tetragonal structure ( $P 4 / n m m$ space group); (b) Typical samples used in this study, in the form of a bar and a coin, were cut along the direction of a cylindrical sample; (c) Powder X-ray diffraction patterns for $\mathrm{Bi}_{1-x} \mathrm{Ca}_{x} \mathrm{CuSeO}$ samples; (d) Rietveld refinement of the $\mathrm{Bi}_{0.925} \mathrm{Ca}_{0.075} \mathrm{CuSeO}$ sample; (e) Room temperature carrier mobility ( $\mu$, circles) and carrier concentration ( $n$, squares) as a function of Ca doping content; (f) Electronic absorption spectra of $\mathrm{Bi}_{1-x} \mathrm{Ca}_{x} \mathrm{CuSeO}$ samples.

of $\mathrm{Bi}_{1-\mathrm{x}} \mathrm{Ca}_{\mathrm{x}} \mathrm{CuSeO}$ samples. All major Bragg peaks exhibit an excellent match with the simulation results for BiCuSeO (PDF \# 82-0464), which can be indexed as a $\mathrm{ZrSiCuAs-type} \mathrm{structure.} \mathrm{Figure} \mathrm{1d} \mathrm{shows}$ the diffraction pattern and Rietveld refinement of the $\mathrm{Bi}_{0.925} \mathrm{Ca}_{0.075}$ CuSeO sample. There is a good fit between the experimental data (black circle) and the calculations (red line), as confirmed by typical $R$ values for all refinements of the $R_{\mathrm{wp}}$ (weighted residual error, black line) factor of $\sim 6.7 \%, R_{\mathrm{p}} \sim 5.9 \%$ and $R_{\mathrm{Bragg}} \sim 2.1 \%$.

The change in lattice parameters as a function of the Ca doping level is shown in Supplementary Figure S1(SI), wherein both $a$ - and $c$ axes increase slightly with increasing $\mathrm{Ca}$ content, which is related to the radius of the $\mathrm{Ca}^{2+}$ ions $(0.99 \AA)$ being larger than that of the $\mathrm{Bi}^{3+}$ ions $(0.96 \AA)$. The Hall carrier concentrations $\left(n_{\mathrm{H}}\right)$ at $300 \mathrm{~K}$ increase rapidly from $1.1 \times 10^{18} \mathrm{~cm}^{-3}$ for pure $\mathrm{BiCuSeO}$ to $8.94 \times$
$10^{20} \mathrm{~cm}^{-3}$ for the sample with $x=0.1 \mathrm{Ca}$, as shown in Figure 1e. Collectively, the lattice parameter variation and carrier concentration indicate that $\mathrm{Ca}^{2+}$ is successfully incorporated into the $\mathrm{BiCuSeO}$ lattice. The electronic absorption of the $\mathrm{BiCuSeO}$ sample corresponds to a band gap of $\sim 0.82 \mathrm{eV}$, Figure 1f, which shifts to a lower energy value when the Ca doping level fraction is within $x=0.05$. A further increase in the Ca doping level to $x=0.075$ and 0.10 results in a structure with no clear band-edge, which indicates that the absorption of metallic conduction electrons decreases the Fermi energy in the valence band due to heavy Ca doping. This result is consistent with the change in the carrier concentrations as a function of Ca doping content in Figure 1e.

Three samples ( $\mathrm{BiCuSeO}, \mathrm{Bi}_{0.975} \mathrm{Ca}_{0.025} \mathrm{CuSeO}$ and $\mathrm{Bi}_{0.925} \mathrm{Ca}_{0.075}$ $\mathrm{CuSeO}$ ) were examined in more detail using TEM. Rod-like grains 

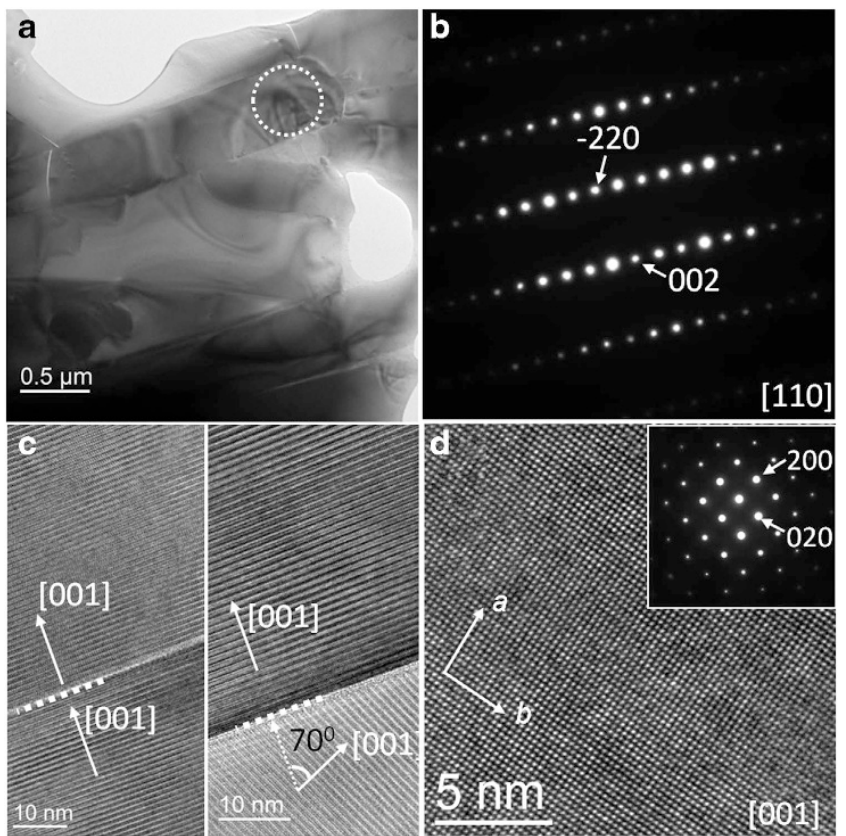

Figure 2 (a) Low magnification TEM image of the BiCuSeO sample; (b) select area electron diffraction from the circled region in (a); (c) highresolution TEM images reveal two typical grain orientations; (d) Highresolution TEM image of the $\mathrm{Bi}_{0.925} \mathrm{Ca}_{0.075} \mathrm{CuSeO}$ sample; the inset is the relative electron diffraction.

were mainly observed without any nanoscale precipitates. Figure $2 \mathrm{a}$ shows the typical low-magnification TEM image of the $\mathrm{BiCuSeO}$ sample. Lamellar structures with an average width of $0.5 \mu \mathrm{m}$ and length of $4.0 \mu \mathrm{m}$ are shown in the image. Figure $2 \mathrm{~b}$ shows an electron diffraction pattern with a selected area aperture of only one grain, which is marked as a circle in Figure 2a and does not show split Bragg spots. The electron diffraction pattern can be easily indexed as the [110] direction of the BiCuSeO sample. The TEM images also reveal a variety of relative orientations, including coherent, semicoherent and incoherent, between the lamellar grains. Different types of grain boundaries will affect electron and phonon scattering differently because of their dissimilar scattering properties. ${ }^{1,8}$ Very flat and sharp boundaries can be observed between the lamellar grains in Figure 2c. In the left part of Figure 2c, the [001] directions of the two grains are parallel to the coherent or semicoherent boundary, but they exhibit an $\sim 70^{\circ}$ rotation with the right part of Figure $2 \mathrm{c}$. Figure $2 \mathrm{~d}$ is an highresolution TEM image of the $\mathrm{Bi}_{0.975} \mathrm{Ca}_{0.025} \mathrm{CuSeO}$ sample along the [001] direction. No nanoscale precipitates were observed along this direction as well. The relative electron diffraction pattern (inset) shows no split spots along the [001] axis, instead revealing two sublattices ( $\mathrm{CuSe}$ and doped $\mathrm{BiO}$ ) that are commensurate rather than incommensurate. These data suggest that $\mathrm{BiCuSeO}$ is not a misfit compound. Figure 3a is a typical lattice image of a grain boundary, which shows a sharp and bright interface. The upper grain image is obtained along the [100] direction, although the direction of the bottom grain is along the [110] direction. Figure $3 \mathrm{~b}$ is the atomic model based on the high-resolution TEM image in Figure 3a, which clearly shows the mismatch and misfit dislocation at the interface, while it may be hard to see the mismatch in the real image. Fast Fourier transforms of images in Figures $3 \mathrm{a}$ and $\mathrm{b}$ are provided in Figures $3 \mathrm{c}$ and $\mathrm{d}$, respectively. The fast Fourier transform images reveal similar spot distributions to those of the parent images.

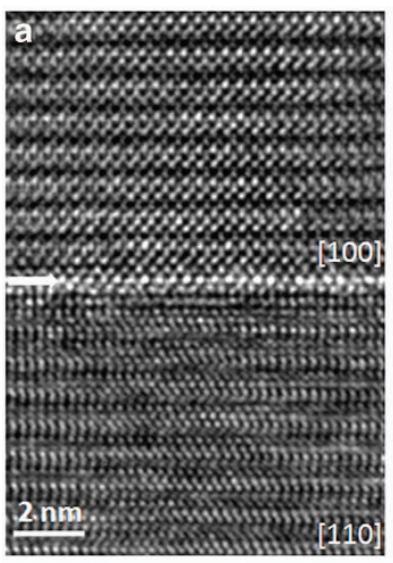

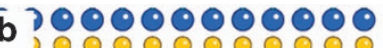

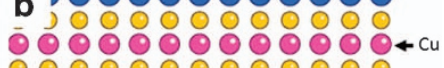
0 0 $00000000000 \%$

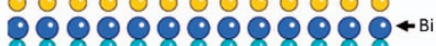
0808808088080

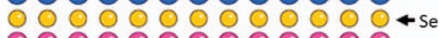

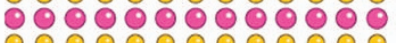

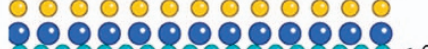
$88888888888888+0$ 000000000000000000 0000000000000 000000000000000000 $8 \times 2 \times 2 \times 2 \times 3 \times 28 \%$ 00000000000000000

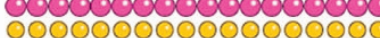

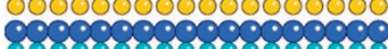

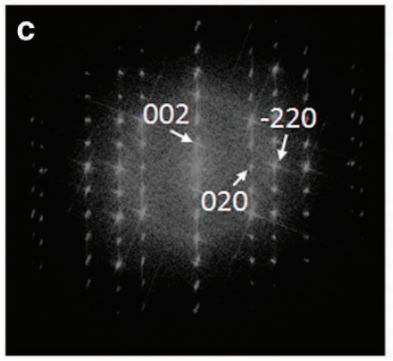

d

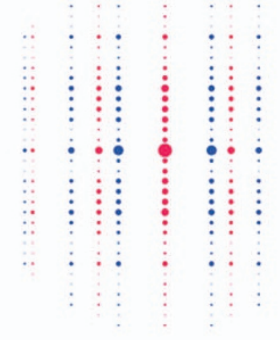

Figure 3 (a) The lattice image shows a good interface between two grains of the BiCuSeO sample; (b) atomic model of the two grains based on [100] (top) and [110] (bottom) directions; (c) and (d) are fast Fourier transform images of (a) and (b), respectively, which reveal a good match.

However, a careful comparison shows split spots along the $c$ direction only in Figure 3c, but not in Figure 3d, which indicates that the strain is partially relaxed in these two grains. ${ }^{1,8}$

The electronic band structure of $\mathrm{BiCuSeO}$ can be determined using the $\mathrm{LDA}+\mathrm{U}(\mathrm{U}=9.0 \mathrm{eV})$ along the high symmetry directions in the Brillouin zone, as shown in Figure 4a. The conduction band minimum is at point $\mathrm{Z}$, and the valence band maximum is on the $\mathrm{M}-\Gamma$ line. The effective mass of $\mathrm{BiCuSeO}$ is obtained by fitting the actual $E-k$ diagram around the conduction band minimum and the valence band maximum, and the effective mass $m^{*}$ is defined as ${ }^{1,2}$ :

$$
m^{*}=\hbar^{2}\left(\frac{\partial^{2} E}{\partial k^{2}}\right)^{-1}
$$

where $\hbar$ is the reduced Planck constant. The calculated effective mass of the valence bands is $\sim 0.54 m_{\mathrm{o}}$ for $\mathrm{BiCuSeO}$ by $\mathrm{LDA}+\mathrm{U}$. The GGA $+\mathrm{U}$ (generalized gradient approximation + Hubbard parameter) calculation indicates an indirect band gap of $0.66 \mathrm{eV}$ for $\mathrm{BiCuSeO}$, which can be comparable to the measured value of $0.82 \mathrm{eV}$ for BiCuSeO (Supplementary Figure S1). Figure 4 b shows the total and partial density of states for $\mathrm{BiCuSeO}$. The valence bands consist of three parts: the first is located at lower energies, which is mainly the $\mathrm{O}-2 \mathrm{~s}$ states. The middle valence bands are dominated by Se-4s and $\mathrm{Bi}-6 \mathrm{~s}$ states. The strong contributions to the upper valence bands are coming from the $\mathrm{O}-2 \mathrm{p}, \mathrm{Cu}-3 \mathrm{~d}$ and $\mathrm{Se}-4 \mathrm{p}$ states. The conduction bands edge is described by $\mathrm{Bi}-6 \mathrm{p}$ states.

Figure 5 shows the thermoelectric properties as a function of temperature for $\mathrm{Bi}_{1-\mathrm{x}} \mathrm{Ca}_{\mathrm{x}} \mathrm{CuSeO}$ samples. As shown in Figure $5 \mathrm{a}$, $\mathrm{BiCuSeO}$ exhibits low electrical conductivity over the entire temperature range and a semiconducting electrical transport behavior. After doping with $\mathrm{Ca}$, the electrical transport changes to a metallic-like behavior and the electrical conductivity shows a significant increase 
a

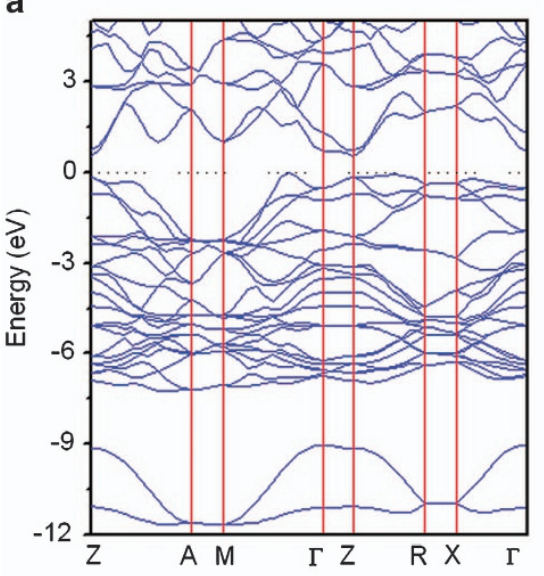

b

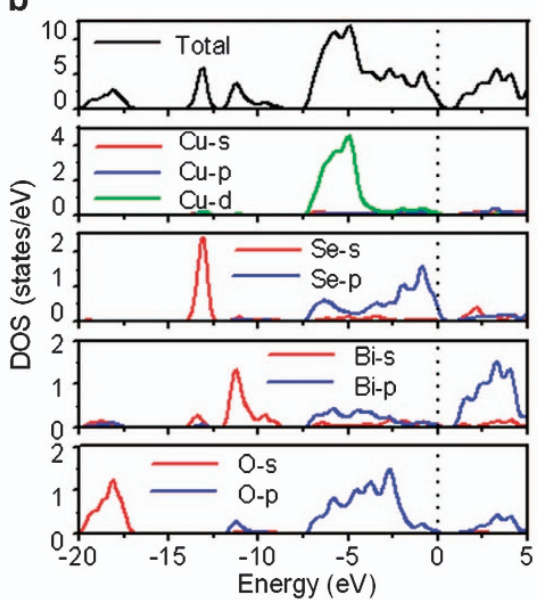

Figure 4 (a) The band structure of BiCuSeO; (b) The total and partial density of states of BiCuSeO.

with increasing $\mathrm{Ca}$ fraction, from $\sim 1.12 \mathrm{~S} \mathrm{~cm}^{-1}$ (BiCuSeO) to $\sim 270 \mathrm{~S} \mathrm{~cm}^{-1}\left(\mathrm{Bi}_{0.90} \mathrm{Ca}_{0.10} \mathrm{CuSeO}\right)$ at $300 \mathrm{~K}$. The electrical conductivity of $\mathrm{Bi}_{0.90} \mathrm{Ca}_{0.10} \mathrm{CuSeO}$ is higher than that of $\mathrm{BiCu}_{0.975} \mathrm{SeO}^{22}$ and is comparable to that of $\mathrm{Bi}_{0.90} \mathrm{Sr}_{0.10} \mathrm{CuSeO}{ }^{21}$ This result indicates that Ca doping can effectively enhance the electrical conductivity of $\mathrm{BiCuSeO}$ by introducing holes in the valence band. Similar to the $\mathrm{LaFeAsO}$ superconductors, ${ }^{32,33}$ the $\mathrm{BiCuSeO}$ compounds consist of $\left(\mathrm{Cu}_{2} \mathrm{Se}_{2}\right)^{2-}$ conducting layers separated by insulating $\left(\mathrm{Bi}_{2} \mathrm{O}_{2}\right)^{2+}$, which act as charge reservoirs. Therefore, the enhanced electrical conductivity of $\mathrm{Bi}_{1-x} \mathrm{Ca}_{x} \mathrm{CuSeO}$ can be explained by the carriers introduced to the $\left(\mathrm{Cu}_{2} \mathrm{Se}_{2}\right)^{2-}$ layers in response to the negative charges in the insulating $\left(\mathrm{Bi}_{2} \mathrm{O}_{2}\right)^{2+}$ layers through partial substitution of $\mathrm{Bi}^{3+}$ by $\mathrm{Ca}^{2+} .21$ The substitution of $\mathrm{Ca}^{2+}$ for $\mathrm{Bi}^{3+}$ leads to a transfer of holes $\left(h^{+}\right)$from the charge reservoir $\left(\mathrm{Bi}_{2} \mathrm{O}_{2}\right)^{2+}$ layers to the conducting $\left(\mathrm{Cu}_{2} \mathrm{Se}_{2}\right)^{2-}$ layers in the following manner:

$$
2\left(\mathrm{Bi}_{1-\mathrm{x}} \mathrm{Ca}_{\mathrm{x}} \mathrm{CuSeO}\right)=\left(\mathrm{Bi}_{2-2 \mathrm{x}} \mathrm{Ca}_{2 \mathrm{x}} \mathrm{O}_{2}\right)^{(2-2 \mathrm{x})+}+\left(\mathrm{Cu}_{2} \mathrm{Se}_{2}\right)^{2-}+2 x h^{+}
$$

where $h^{+}$is the produced holes introduced by Ca doping. If we assume that each $\mathrm{Ca}$ promotes one hole $h^{+}$to the valence band, when $x=0.1 \mathrm{Ca}$, there are 0.2 holes per unit cell ( $2 \mathrm{BiCuSeO}$ units per unit cell). The volume of the unit cell is approximately $138 \AA^{3}$ (from $\mathrm{X}$-ray diffraction), which should lead to a carrier concentration of $\sim 1.45 \times 10^{21} \mathrm{~cm}^{-3}$. Indeed, the obtained carrier concentration of $8.94 \times 10^{20} \mathrm{~cm}^{-3}$ is observed for the sample with $x=0.1 \mathrm{Ca}$ doping, which indicates that the small amount of $\mathrm{Ca}$ is not introduced into the structure or that the carrier concentration difference comes from the starting powers purity, experimental measurement error and composition homogeneity, among other effects.

Doping with $\mathrm{Ca}$ also produces a significant effect on the Seebeck coefficient of BiCuSeO system, as shown in Figure 5b. A positive Seebeck coefficient indicates p-type electrical transport behavior. The Seebeck coefficients for $\mathrm{BiCuSeO}$ are large, for example, + $330 \mu \mathrm{VK}^{-1}$ at $300 \mathrm{~K}$ and $+410 \mu \mathrm{VK}^{-1}$ at $923 \mathrm{~K}$, and decrease with increasing $\mathrm{Ca}$ doping fractions but still remain high over the entire temperature range of $+120 \mu \mathrm{VK}^{-1}$ at $300 \mathrm{~K}$ to $+198 \mu \mathrm{VK}^{-1}$ at $923 \mathrm{~K}$ for the $\mathrm{Bi}_{0.90} \mathrm{Ca}_{0.10} \mathrm{CuSeO}$ sample. The increase in the Seebeck coefficient may be related to the layered crystal structure wherein insulating $\left(\mathrm{Bi}_{2} \mathrm{O}_{2}\right)^{2+}$ and conductive $\left(\mathrm{Cu}_{2} \mathrm{Se}_{2}\right)^{2-}$ layers alternate forming a natural superlattice with a two-dimensional confinement of charge carriers. The natural layered structure of $\left(\mathrm{Bi}_{2} \mathrm{O}_{2}\right)^{2+}$ / $\left(\mathrm{Cu}_{2} \mathrm{Se}_{2}\right)^{2-} /\left(\mathrm{Bi}_{2} \mathrm{O}_{2}\right)^{2+}$ is very similar to the two-dimensional electron gas structure of $\mathrm{SrTiO}_{3} / \mathrm{SrTi}_{0.8} \mathrm{Nb}_{0.2} \mathrm{O}_{3} / \mathrm{SrTiO}_{3}$, containing artificial insulating/conductive/insulating layers, which exhibits a high Seebeck coefficient. $^{34}$ The calculation of the electronic density of states for $\mathrm{BiCuSeO}$ indicates a large Seebeck coefficient resulting from a large effective mass $\left(m^{*}\right)$. To further verify this assumption, the effective mass $\left(m^{*}\right)$ was also calculated according to the following equations using the observed carrier concentration $(n)$ and Seebeck coefficient (S) values ${ }^{35}$ :

$$
\begin{aligned}
& m^{*}=\frac{h^{2}}{2 k_{\mathrm{B}} T}\left[\frac{n}{4 \pi F_{1 / 2}(\eta)}\right]^{2 / 3} \\
& S= \pm \frac{k_{\mathrm{B}}}{e}\left(\frac{(r+3 / 2) F_{\mathrm{r}+3 / 2}(\eta)}{(r+3 / 2) F_{\mathrm{r}+1 / 2}(\eta)}-\eta\right) \\
& F_{\mathrm{n}}(\eta)=\int_{0}^{\infty} \frac{\chi^{n}}{1+e^{\chi-\eta}} d \chi
\end{aligned}
$$

where $F_{\mathrm{n}}(\eta)$ is the $n$-th order Fermi integral, $k_{\mathrm{B}}$ is the Boltzmann constant, $e$ is the electron charge, $h$ is the Planck constant and $r$ is the scattering factor. Usually, this calculation is assumed based on a single parabolic band with three-dimensional transport character. In this study, $\mathrm{BiCuSeO}$ polycrystalline samples were examined at a random grain orientation because it is difficult to extract the directional dependence of the physical properties for a polycrystalline sample. Therefore, all values provided in this paper are averaged estimates. The scattering factor $(r)$ is $-1 / 2$ as the acoustic phonon scattering is independent of the grain size and is generally assumed to be the main scattering mechanism at room temperature. ${ }^{8,36}$ The reduced Fermi energy $\eta$ was determined based on the fitting of respective Seebeck values (the details are provided in the SI). The calculation provides an effective mass $\left(\mathrm{m}^{*}\right)$ of $\sim 0.60 \mathrm{~m}_{\mathrm{o}}$, which is consistent with $0.54 \mathrm{~m}_{\mathrm{o}}$ determined by density of state calculations and higher than that of $\operatorname{PbTe}\left(0.24 m_{\mathrm{o}}\right)^{37}$ and $\mathrm{PbS}\left(0.40 \mathrm{~m}_{\mathrm{o}}\right)^{8}$ with a rock salt structure. The combined electrical conductivity and positive temperature-dependent Seebeck coefficient result in a power factor $\left(S^{2} \sigma\right)$ peak at a high temperature of $923 \mathrm{~K}$. As shown in Figure $5 \mathrm{c}$, the highest power factor is $\sim 4.74 \mu \mathrm{W} \mathrm{cm}{ }^{-1} \mathrm{~K}^{-2}$ for the $\mathrm{Bi}_{0.925} \mathrm{Ca}_{0.075} \mathrm{CuSeO}$ sample at $923 \mathrm{~K}$, 
a

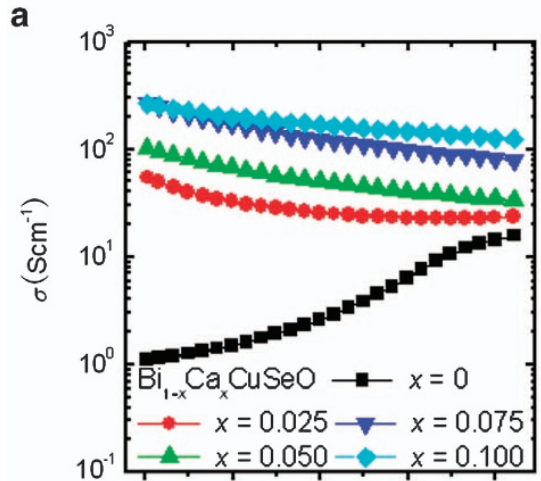

C

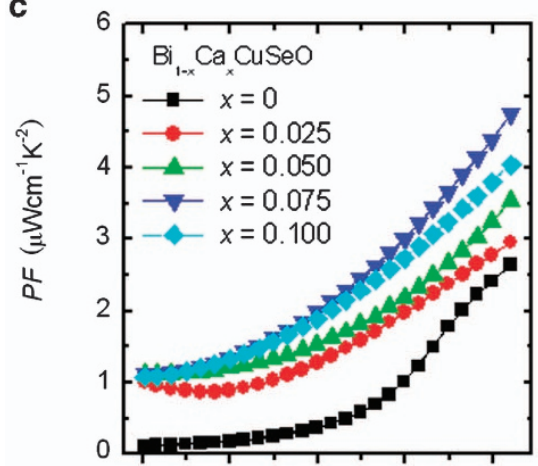

e

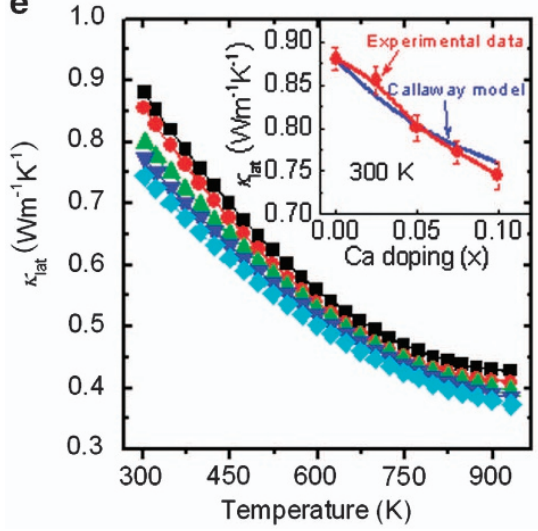

b
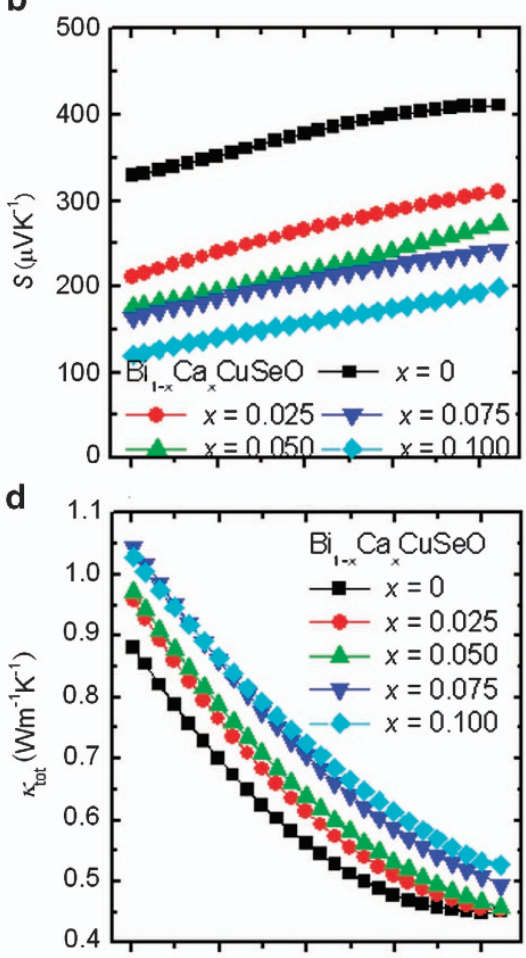

$f$

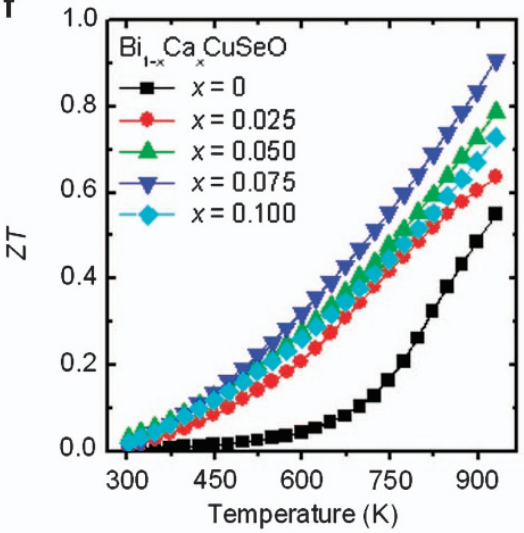

Figure 5 Thermoelectric properties of $\mathrm{Bi}_{1-x} \mathrm{Ca}_{x} \mathrm{CuSeO}$ as a function of temperature: (a) electrical conductivity; (b) Seebeck coefficient; (c) power factor; (d) total thermal conductivity; (e) lattice thermal conductivity, wherein the insert provides a comparison of the experimental lattice thermal conductivity at $300 \mathrm{~K}$ and the calculated conductivity determined using Callaway's model; (f) Figure of merit, $Z T$.

which is higher than $\sim 4.10 \mu \mathrm{W} \mathrm{cm}{ }^{-1} \mathrm{~K}^{-2}$ at $923 \mathrm{~K}$ for the $\mathrm{BiCu}_{0.975}$ SeO sample. ${ }^{22}$

Figure $5 \mathrm{~d}$ shows the total thermal conductivity as a function of temperature for $\mathrm{Bi}_{1-\mathrm{x}} \mathrm{Ca}_{\mathrm{x}} \mathrm{CuSeO}$ samples. The total thermal conductivity of undoped $\mathrm{BiCuSeO}$ decreases with increasing temperature from $0.89 \mathrm{Wm}^{-1} \mathrm{~K}^{-1}$ at $300 \mathrm{~K}$ to $0.45 \mathrm{Wm}^{-1} \mathrm{~K}^{-1}$ at $923 \mathrm{~K}$ (heat capacity (Supplementary Figure S2) and thermal diffusivity (Supplementary Figure S3)). This total thermal conductivity is very low and comparable to other high-performance thermoelectric materials, ${ }^{1-3}$ even lower than that of nanostructured Bi-Sb-Te. ${ }^{6}$ The total thermal conductivity increases with increasing $\mathrm{Ca}$ content but still maintains low over the entire measuring temperature range, for example, $1.05 \mathrm{Wm}^{-1} \mathrm{~K}^{-1}$ at $300 \mathrm{~K}$ and $0.52 \mathrm{Wm}^{-1} \mathrm{~K}^{-1}$ at $923 \mathrm{~K}$ for the $\mathrm{Bi}_{0.90} \mathrm{Ca}_{0.10} \mathrm{CuSeO}$ sample. Generally, the lattice thermal conductivity $\kappa_{\text {lat }}$ can be estimated by directly subtracting the electronic thermal conductivity $\kappa_{\text {ele }}$ from the total thermal conductivity $\kappa_{\text {tot }}$. The electronic part $\kappa_{\text {ele }}$ is proportional to the electrical conductivity $\sigma$ through the Wiedemann-Franz relation, $\kappa_{\text {ele }}=L \sigma T$, where $L$ is the Lorenz number obtained from fitting the respective Seebeck coefficient values with an estimate of the reduced chemical potential $(\eta),{ }^{38,39}$ as shown in Supplementary Figure S4 (Lorenz number calculation details can be found in the SI; the electronic thermal conductivity $\kappa_{\text {ele }}$ is shown in Supplementary Figure $\mathrm{S} 5)$. Figure $4 \mathrm{e}$ shows the lattice thermal conductivity as a function of temperature for $\mathrm{Bi}_{1-\mathrm{x}} \mathrm{Ca}_{\mathrm{x}} \mathrm{CuSeO}$ samples. $\mathrm{BiCuSeO}$ shows a very low lattice thermal conductivity of $0.88 \mathrm{Wm}^{-1} \mathrm{~K}^{-1}$ at $300 \mathrm{~K}$ and $0.43 \mathrm{~W} \mathrm{~m}^{-1} \mathrm{~K}^{-1}$ at $923 \mathrm{~K}$, which is much lower than those of PbTebased thermoelectrics. ${ }^{3,7,8,36}$ The possible origin of the intrinsically low thermal conductivity of $\mathrm{BiCuSeO}$ will be discussed later in this paper. As the thermal conductivity values are very low, it is worth 
comparing them with the calculated minimum lattice thermal conductivity $\kappa_{\text {lat,min }}$ for $\mathrm{BiCuSeO}$ to assess if there is still room for improvement. The lattice thermal conductivity $\kappa_{\text {lat }}$ can be estimated by the following relationship ${ }^{11,14,18}$ :

$$
\kappa_{\text {lat }}=\frac{1}{3} C_{\mathrm{v}} v_{\mathrm{a}} l
$$

where the $C_{\mathrm{v}}$ is the molar specific heat at constant volume, $l$ is the mean free path of phonons, and $v_{\mathrm{a}}$ is the average sound velocity, which is defined as follows ${ }^{12,40 .}$

$$
v_{\mathrm{a}}=\left(\frac{1}{3}\left[\frac{1}{v_{1}^{3}}+\frac{2}{v_{\mathrm{s}}^{3}}\right]\right)^{-1 / 3}
$$

$v_{\mathrm{a}}$ is determined using the longitudinal $\left(v_{\mathrm{l}}\right)$ and transverse $\left(v_{\mathrm{s}}\right)$ sound velocities provided in Table 1 . The minimal lattice thermal conductivity $\kappa_{\text {lat }}$ has been estimated by the minimum $l$ to be the interatomic distance ${ }^{11,14,18}$ of $\sim 3.0 \AA$ for the $\mathrm{BiCuSeO}$ system. Using equation (6), $\kappa_{\text {lat,min }}$ of $0.47 \mathrm{~W} \mathrm{~m}^{-1} \mathrm{~K}^{-1}$ is obtained at $300 \mathrm{~K}$, it is much lower than the value of $0.88 \mathrm{Wm}^{-1} \mathrm{~K}^{-1}$ obtained in this study, suggesting a possibility for further reduction of $\kappa_{\text {lat }}$ in $\mathrm{BiCuSeO}$.

The lattice thermal conductivity $\kappa_{\text {lat }}$ is presumably reduced by point defect scattering through Ca doping. Indeed, a clear trend can be readily observed where the lattice thermal conductivity $\kappa_{\text {lat }}$ decreases with increasing $\mathrm{Ca}$ content. Namely, the lattice thermal conductivity $\kappa_{\text {lat }}$ at $300 \mathrm{~K}$ decreases from $0.88 \mathrm{Wm}^{-1} \mathrm{~K}^{-1}$ for the undoped $\mathrm{BiCuSeO}$ to $0.75 \mathrm{Wm}^{-1} \mathrm{~K}^{-1}$ for the $\mathrm{Bi}_{0.90} \mathrm{Ca}_{0.10} \mathrm{CuSeO}$ sample. To understand the role of point defects in reducing the $\kappa_{\text {lat }}$ of $\mathrm{Bi}_{1-x} \mathrm{Ca}_{x} \mathrm{CuSeO}$, we performed theoretical calculations based on the Callaway model, ${ }^{40,41}$ wherein point defect scattering in a solid solution system originates from both mass difference (mass fluctuations) as well as differences in size and interatomic coupling forces (strain field fluctuations) between the impurity atom and the host lattice. Herein, we present a phonon scattering model based on the Callaway model ${ }^{40,41}$ and try to describe the effect of Ca doping on the lattice thermal conductivity $\kappa_{\text {lat }}$.

At temperatures above the Debye temperature, the ratio of the lattice thermal conductivities of a material containing point defects with that of the parent material can be written in the following manner: ${ }^{40,41}$

$$
\frac{\kappa_{\text {lat }}}{\kappa_{\text {lat }, \mathrm{p}}}=\frac{\tan ^{-1}(u)}{u}
$$

where $\kappa_{\text {lat }}$ and $\kappa_{\text {lat,p }}$ are the lattice thermal conductivities of the doped and parent materials, respectively, and the parameter $u$ is defined as follows: ${ }^{40,41}$

$$
u=\left(\frac{\pi^{2} \theta_{\mathrm{D}} \Omega}{h v_{\mathrm{a}}^{2}} \kappa_{\mathrm{L}, \mathrm{p}} \Gamma\right)^{1 / 2}
$$

where $h, \Omega, v_{\mathrm{a}}$ and $\theta_{\mathrm{D}}$ are the Planck constant, the average volume per

\section{Table 1 Elastic properties of $\mathrm{BiCuSeO}$ at room temperature}

\begin{tabular}{lcc}
\hline Parameters & & \\
Longitudinal sound velocity & $v_{l}\left(\mathrm{~ms}^{-1}\right)$ & 3290 \\
Transverse sound velocity & $v_{S}\left(\mathrm{~m} \mathrm{~s}^{-1}\right)$ & 1900 \\
Average sound velocity & $v_{a}\left(\mathrm{~ms}^{-1}\right)$ & 2107 \\
Young's modulus & $E(\mathrm{GPa})$ & 76.5 \\
Debye temperature & $\theta_{\mathrm{D}}(\mathrm{K})$ & 243 \\
Poisson ratio & $v_{\mathrm{p}}$ & 0.25 \\
Gruneisen parameter & $\gamma$ & 1.50 \\
\hline
\end{tabular}

atom, the average sound velocity, and the Debye temperature, respectively. The imperfection scaling parameter $\Gamma$ in equation (9) represents the strength of point defects phonon scattering, which includes two components: the scattering parameter due to mass fluctuations $\Gamma_{\mathrm{M}}$ and the scattering parameter due to strain field fluctuations $\Gamma_{S}$. A phenomenological adjustable parameter $\varepsilon$ is always included; because of the uncertainty of $\Gamma_{S}$, one writes $\Gamma=\Gamma_{M}+\varepsilon \Gamma_{S}$. The calculation of point defect scattering based on the Callaway model (calculation details can be found in the SI), exhibits excellent agreement between the calculated and measured values, as shown in the inset of Figure 5e. Thus, the reduction in the lattice thermal conductivity by $\mathrm{Ca}$ doping is confirmed by both experimental results and theoretical calculations.

Using the electrical and thermal transport properties, the dimensionless figure of merit $(Z T)$ is calculated as shown in Figure $5 f$. The $Z T$ shows an increasing trend with temperature, and a maximum $Z T$ value of 0.9 is achieved at $923 \mathrm{~K}$ for the $\mathrm{Bi}_{0.925} \mathrm{Ca}_{0.075} \mathrm{CuSeO}$ sample, which is higher than that of 0.8 at $923 \mathrm{~K}$ for $\mathrm{BiCu}_{0.975} \mathrm{SeO}^{22}$ The $Z T$ value of $\mathrm{Bi}_{0.925} \mathrm{Ca}_{0.075} \mathrm{CuSeO}$ at $873 \mathrm{~K}$ is also higher than that of 0.7 for $\mathrm{Bi}_{0.90} \mathrm{Sr}_{0.10} \mathrm{CuSeO}$ at $873 \mathrm{~K}^{21}$ The present $Z T$ of 0.9 is higher than most thermoelectric materials with intrinsically low thermal conductivity reported so far. ${ }^{13-20}$ Therefore, it can be concluded that the higher thermoelectric performance of $\mathrm{BiCuSeO}$ is mainly due to the intrinsically low thermal conductivity of the material.

\section{Origin of the low thermal conductivity}

Our results suggest that the electrical transport properties of the $\mathrm{BiCuSeO}$ system are actually significantly lower than those of other thermoelectrics, for example, $\mathrm{Bi}_{2} \mathrm{Te}_{3}$-based, ${ }^{6,9,36}$ PbTe-based, ${ }^{3,7,8}$ skutterudites, ${ }^{42}$ and metallic-based layered misfit sulfides. ${ }^{43}$ Thus, the high thermoelectric performance of the $\mathrm{BiCuSeO}$ system is mainly due to the intrinsically low thermal conductivity. To clarify the origin of the intrinsically low thermal conductivity, the elastic properties of $\mathrm{BiCuSeO}$ compounds were analyzed. Young's modulus $(E)$ value of $\mathrm{BiCuSeO}$ was extracted from the longitudinal $\left(v_{1}\right)$ and transverse $\left(v_{\mathrm{s}}\right)$ sound velocities. ${ }^{23}$ Young's modulus is related to the stiffness of a material's individual atomic bonds. ${ }^{12,36}$ Weaker interatomic bonding generally results in lower stiffness and a lower Young's modulus. The materials with a low Young's modulus are considered to have 'soft' bonding, which will result in a slow transport of phonons, and thus a lower lattice thermal conductivity. ${ }^{44}$ Indeed, $\mathrm{BiCuSeO}$ exhibits a lower sound velocity, ${ }^{23}$ Young's modulus and lattice thermal conductivity at $300 \mathrm{~K}$ than other oxides, ${ }^{40,45}$ namely, BiCuSeO $\left(2107 \mathrm{~ms}^{-1}, 76.5 \mathrm{GPa}\right.$, $\left.0.9 \mathrm{~W} \mathrm{~m}^{-1} \mathrm{~K}^{-1}\right)$ are lower than those of $\mathrm{Ba}_{2} \mathrm{YbAlO}_{5}\left(2901 \mathrm{~m} \mathrm{~s}^{-1}\right.$, 109.4 GPa, $\left.1.4 \mathrm{Wm}^{-1} \mathrm{~K}^{-1}\right)$, those of $\mathrm{Ba}_{2} \mathrm{DyAlO}_{5}\left(3078 \mathrm{~m} \mathrm{~s}^{-1}\right.$, 116.5 GPa, $\left.1.8 \mathrm{Wm}^{-1} \mathrm{~K}^{-1}\right)$ and those of $\mathrm{Gd}_{2} \mathrm{Zr}_{2} \mathrm{O}_{7}\left(3832 \mathrm{~ms}^{-1}\right.$, $\left.234.3 \mathrm{GPa}, 2.2 \mathrm{Wm}^{-1} \mathrm{~K}^{-1}\right)$.

In addition to the analysis of Young's modulus $(E)$, which is related to the chemical bonding strength, the Gruneisen parameter $(\gamma)$ is also relevant in evaluating the intrinsically low thermal conductivity. ${ }^{11,18}$ The Gruneisen parameter $(\gamma)$ is often referred to as a temperaturedependent anharmonicity parameter that reflects how much phonon vibrations in a crystal lattice deviate from harmonic oscillations. Anharmonicity of the chemical bond drives the phonon-phonon umklapp and normal processes that limit the lattice thermal conductivity. ${ }^{46}$ In this paper, the Gruneisen parameter $(\gamma)$ of $\mathrm{BiCuSeO}$ has been calculated using the following relationship: ${ }^{47}$

$$
\gamma=\frac{3}{2}\left(\frac{1+v_{\mathrm{p}}}{2-3 v_{\mathrm{p}}}\right)
$$


where the Poisson ratio $\left(v_{\mathrm{p}}\right)$ can be derived from the longitudinal $\left(v_{1}\right)$ and transverse $\left(v_{\mathrm{s}}\right)$ sound velocities using the following relationship ${ }^{40,47}$ :

$$
v_{\mathrm{p}}=\frac{1-2\left(v_{\mathrm{s}} / v_{1}\right)^{2}}{2-2\left(v_{\mathrm{s}} / v_{1}\right)^{2}}
$$

The Gruneisen parameter $(\gamma)$ was calculated to be $\sim 1.5$ for $\mathrm{BiCuSeO}$, which is a fairly large value for a compound with the potential to be a low thermal conductivity material, indicating a high degree of anharmonicity in the crystal lattices of the BiCuSeO system. This value is comparable to or even a bit higher than that (1.45) of PbTe. ${ }^{44}$ The large Gruneisen parameter $(\gamma)$ value of PbTe likely results from octahedral atomic coordination in the rock salt crystal structure and a high coordination number. The associated high anharmonicity results from a rather low value of $\kappa_{\text {lat }}{ }^{46,48}$ This behavior was recently explained in terms of local structural distortions in $\mathrm{PbTe}$, which is close to its ferroelectric phase transition, leading to bonding anharmonicity. ${ }^{49}$

A large Gruneisen parameter $(\gamma)$ leads to a lower thermal conductivity, along with a larger Seebeck coefficient, resulting in improved performance of $\mathrm{PbTe}$ in comparison with other thermoelectrics. ${ }^{1,2}$ Morelli et al. ${ }^{11}$ reported that the intrinsically low thermal conductivity of $\mathrm{AgSbTe}_{2}$ results from an extremely high Gruneisen parameter $(\gamma)$ value of 2.05. The high Gruneisen parameter $(\gamma)$, linked to the anharmonicity, may originate from the presence of nonbonding valence electrons in the $s p$-hybridized bonding orbital. ${ }^{11,15}$ These non-bonding electrons, originating from the valence shell of $\mathrm{Sb}$, give rise to electron clouds surrounding the $\mathrm{Sb}$ atoms that cause nonlinear repulsive forces, which is manifested as an anharmonicity. ${ }^{11,15}$ As it is in the same group as $\mathrm{V}, \mathrm{Bi}$ exhibits a larger atom radius than that of $\mathrm{Sb}$, making its valence shell and the electron clouds surrounding the $\mathrm{Bi}$ atoms larger than those of $\mathrm{Sb},{ }^{11,15,46}$ Similarly low lattice thermal conductivity should be observed in the Bi-based compounds, ${ }^{50}$ in which the $\mathrm{Bi}$ ion formally adopts a trivalent state as in the case of $\mathrm{Sb}$ in $\mathrm{AgSbTe}_{2}$. The connection between the nature of the bonding and the Grüneisen parameter $(\gamma)$ has been explored in detail theoretically by Huang et al. ${ }^{51}$ who clearly show the effect of large electron clouds on anharmonicity. In addition, the lone pair of electrons on Bi possibly lead to more asymmetric electron density and a stronger lattice vibration energy. ${ }^{52}$ We speculate that the very low thermal conductivity and high Gruneisen parameter $(\gamma)$ of 1.5 in the $\mathrm{BiCuSeO}$ system are due in part to the increased bond anharmonicity associated with the presence of trivalent $\mathrm{Bi}^{50}$

In addition to the Young's modulus and Gruneisen parameter $(\gamma)$ for the $\mathrm{BiCuSeO}$ system, other possible reasons include the layered structure, as the phonons can be confined to scattered layer interfaces, ${ }^{53}$ and the presence of heavy elements, ${ }^{1,2}$ among others. All of these features can be summarized as involving heavy atoms with 'soft' bonding, which meet the requirements for a low thermal conductivity selection, as suggested by Clarke..$^{54}$

\section{CONCLUDING REMARKS}

High-performance thermoelectric devices based on the $\mathrm{BiCuSeO}$ system were achieved due to an intrinsically low thermal conductivity of the materials, which was further reduced by Ca doping. The elastic properties indicate that the intrinsically low thermal conductivity is most likely a result of the weak chemical bonding between the two different layers and the strong anharmonicity of the bonding arrangement in the $\mathrm{BiCuSeO}$ crystal structure. The figure of merit, $Z T$, increased significantly from 0.53 for pure $\mathrm{BiCuSeO}$ to 0.9 for
$\mathrm{Bi}_{0.925} \mathrm{Ca}_{0.075} \mathrm{CuSeO}$ at $923 \mathrm{~K}$, which is higher than that of most thermoelectric materials with intrinsically low thermal conductivity reported thus far. ${ }^{13-20}$ These results suggest that the $\mathrm{BiCuSeO}$ system is a robust candidate for medium-temperature thermoelectric applications. Further improvement in the $Z T$ may be achieved by increasing the electrical conductivity via heavy hole doping either using conductive $\left(\mathrm{Cu}_{2} \mathrm{Se}_{2}\right)^{2-}$ layers or insulating $\left(\mathrm{Bi}_{2} \mathrm{O}_{2}\right)^{2+}$ layers and/or by improving the carrier mobility.

\section{ACKNOWLEDGEMENTS}

The authors (L-D Zhao and JQ He) are grateful to Professor Mercouri G Kanatzidis for helpful discussions and thermoelectric measurements performed in his group. This work is supported by the National Natural Science Foundation of China (No. 51202008) (YL Pei) and 973 program of China (No. 2013CB632503) (J-F Li). J He would like to thank the funding of a start-up research project from Xi'an Jiaotong University. The TEM work was performed at the (EPIC) (NIFTI) (Keck-II) facility of the NUANCE Center at Northwestern University. The NUANCE Center is supported by NSF-NSEC, NSF-MRSEC, Keck Foundation, the State of Illinois, and Northwestern University.

1 Kanatzidis, M. G. Nanostructured thermoelectrics: the new paradigm? Chem. Mater 22, 648-659 (2010)

2 Li, J. F., Liu, W. S., Zhao, L. D. \& Zhou, M. High-performance nanostructured thermoelectric materials. NPG Asia Mat. 2, 152-158 (2010).

3 Heremans, J. P., Jovovic, V., Toberer, E. S., Saramat, A., Kurosaki, K., Charoenphakdee, A., Yamanaka, S. \& Snyder, G. J. Enhancement of thermoelectric efficiency in PbTe by distortion of the electronic density of states. Science 321, 554-557 (2008).

4 Harman, T. C., Taylor, P. J., Walsh, M. P. \& LaForge, B. E. Quantum dot superlattice thermoelectric materials and devices. Science 297, 2229-2232 (2002).

5 Heremans, J. P., Thrush, C. M. \& Morelli, D. T. Thermopower enhancement in lead telluride nanostructures. Phys. Rev. B 70, 115334 (2004).

6 Poudel, B., Hao, Q., Ma, Y., Lan, Y., Minnich, A., Yu, B., Yan, X., Wang, D., Muto, A. Vashaee, D., Chen, X., Liu, J., Dresselhaus, M. S., Chen, G. \& Ren, Z. F. Highthermoelectric performance of nanostructured bismuth antimony telluride bulk alloys. Science 320, 634-638 (2008).

7 Hsu, K. F., Loo, S., Guo, F., Chen, W., Dyck, J. S., Uher, C., Hogan, T., Polychroniadis, E. K. \& Kanatzidis, M. G. Cubic AgPbmSbTe2 + m: bulk thermoelectric materials with high figure of merit. Science 303, 818-821 (2004).

8 Zhao, L. D., Lo, S., He, J., Li, H., Biswas, K., Androulakis, J., Wu, C. I., Hogan, T. P., Chung, D. Y., Dravid, V. P. \& Kanatzidis, M. G. High performance thermoelectrics from earth-abundant materials: enhanced figure of merit in $\mathrm{PbS}$ by second phase nanostructures. J. Am. Chem. Soc. 133, 20476-20487 (2011).

9 Zhao, L. D., Zhang, B. P., Li, J. F., Zhou, M., Liu, W.-S. \& Liu, J. Thermoelectric and mechanical properties of nano-SiC-dispersed $\mathrm{Bi} 2 \mathrm{Te} 3$ fabricated by mechanical alloying and spark plasma sintering. J. Alloys Compd 455, 259-264 (2008).

10 Wang, H., Li, J. F., Zou, M. M. \& Sui, T. Synthesis and transport property of AgSbTe2 as a promising thermoelectric compound. Appl. Phys. Lett. 93, 202106 (2008).

11 Morelli, D. T., Jovovic, V. \& Heremans, J. P. Intrinsically minimal thermal conductivity in cubic I-V-VI2 semiconductors. Phys. Rev. Lett. 101, 035901 (2008).

12 Kurosaki, K., Kosuga, A., Muta, H., Uno, M. \& Yamanaka, S. Ag9TITe5: a highperformance thermoelectric bulk material with extremely low thermal conductivity. Appl. Phys. Lett. 87, 061919 (2005).

13 Yusufu, A., Kurosaki, K., Kosuga, A., Sugahara, T., Ohishi, Y., Muta, H. \& Yamanaka, S. Thermoelectric properties of Ag1-xGaTe2 with chalcopyrite structure. Appl. Phys. Lett. 99, 061902 (2011)

14 Zhou, T., Lenoir, B., Colin, M., Dauscher, A., Orabi, R. A. R. A., Gougeon, P., Potel, M. \& Guilmeau, E. Promising thermoelectric properties in AgxMo9Se11 compounds (3.4 $<=x<=3.9$ ). Appl. Phys. Lett. 98, 162106 (2011)

15 Skoug, E. J., Cain, J. D. \& Morelli, D. T. High thermoelectric figure of merit in the Cu3SbSe4-Cu3SbS4 solid solution. Appl. Phys. Lett. 98, 261911 (2011).

16 Plirdpring, T., Kurosaki, K., Kosuga, A., Ishimaru, M., Harnwunggmoung, A., Sugahara, T., Ohishi, Y., Muta, H. \& Yamanaka, S. High-temperature thermoelectric properties of Cu2Ga4Te7 with defect zinc-blende structure. Appl. Phys. Lett. 98, 172104 (2011).

17 Liu, M. L., Chen, I. W., Huang, F. Q. \& Chen, L. D. Improved thermoelectric properties of Cu-doped quaternary chalcogenides of Cu2CdSnSe4. Adv. Mater. 21, 3808-3812 (2009).

18 Cho, J. Y., Shi, X., Salvador, J. R., Meisner, G. P., Yang, J., Wang, H., Wereszczak, A. A. Zhou, X. \& Uher, C. Thermoelectric properties and investigations of low therma conductivity in Ga-doped Cu2GeSe3. Phys. Rev. B 84, 085207 (2011).

19 Chung, D. Y., Hogan, T., Brazis, P., Rocci-Lane, M., Kannewurf, C., Bastea, M., Uher, C. \& Kanatzidis, M. G. CsBi4Te6: a high performance thermoelectric material for low temperature applications. Science 287, 1024-1027 (2000). 
20 Chung, D. Y., Choi, K. S., Iordanidis, L., Schindler, J. L., Brazis, P. W., Kannewurf, C. R., Chen, B., Hu, S., Uher, C. \& Kanatzidis, M. G. High thermopower and low thermal conductivity in semiconducting ternary K-Bi-Se compounds. Synthesis and properties of b-K2Bi8Se13 and K2.5Bi8.5Se14 and their Sb analogs. Chem. Mater. 9, 30603071 (1997).

21 Zhao, L. D., Berardan, D., Pei, Y. L., Byl, C., Pinsard-Gaudart, L. \& Dragoe, N. Bi1xSrxCuSeO oxyselenides as promising thermoelectric materials. Appl. Phys. Lett. 97, 092118 (2010).

22 Liu, Y., Zhao, L. D., Liu, Y. C., Lan, J. L., Xu, W., Li, F., Zhang, B. P., Berardan, D., Dragoe, N., Lin, Y. H., Nan, C. W., Li, J. F. \& Zhu, H. M. Remarkable enhancement in thermoelectric performance of BiCuSeO by $\mathrm{Cu}$ deficiencies. J. Am. Chem. Soc. 133, 20112-20115 (2011).

23 Li, F., Li, J. F., Zhao, L. D., Xiang, K., Liu, Y., Zhang, B. P., Lin, Y. H., Nan, C. W. \& Zhu, H. M. Polycrystalline BiCuSeO oxide as a potential thermoelectric material. Energy Environ. Sci. 5, 7188-7195 (2012).

24 Li, J., Sui, J. H., Pei, Y. L., Barreteau, C., Berardan, D., Dragoe, N., He, J. Q. \& Zhao, L. D. A high thermoelectric figure of merit $\mathrm{ZT}>1$ in $\mathrm{Ba}$ heavily doped $\mathrm{BiCuSeO}$ oxyselenides. Energy Environ. Sci. 5, 8543-8547 (2012).

25 Barreteau, C., Berardan, D., Amzallag, E., Zhao, L. D. \& Dragoe, N. Structural and electronic transport properties in Sr-doped BiCuSeO. Chem. Mater. 24, 3168-3178 (2012).

26 Asmani, M., Kermel, C., Leriche, A. \& Ourak, M. Influence of porosity on Young's modulus and Poisson's ratio in alumina ceramics. J. Eur. Ceram. Soc. 21, 1081-1086 (2001).

27 Clark, S. J., Segall, M. D., Pickard, C. J., Hasnip, P. J., Probert, M. J., Refson, K. \& Payne, M. C. First principles methods using CASTEP. Z. Kristallogr. 220, 567-570 (2005).

28 Liu, Q. J. \& Liu, Z. T. First-principles generalized gradient approximation plus U study of cubic CuAl204. Appl. Phys. Lett. 99, 091902 (2011).

29 Monkhorst, H. J. \& Pack, J. D. Special points for Brillouin-zone integrations. Phys. Rev. B 13, 5188-5192 (1976).

30 Hiramatsu, H., Yanagi, H., Kamiya, T., Ueda, K., Hirano, M. \& Hosono, H. Crystal structures, optoelectronic properties, and electronic structures of layered oxychalcogenides MCuOCh $(\mathrm{M}=\mathrm{Bi}$, $\mathrm{La} ; \mathrm{Ch}=\mathrm{S}, \mathrm{Se}, \mathrm{Te})$ : Effects of electronic configurations of M3 + ions. Chem. Mater. 20, 326-328 (2008).

31 Stampler, E. S., Sheets, W. C., Bertoni, M. I., Prellier, W., Mason, T. O. \& Poeppelmeier, K. R. Temperature driven reactant solubilization synthesis of BiCuOSe. Inorg. Chem. 47, 10009-10016 (2008).

32 Quebe, P., Terbuchte, L. J. \& Jeitschko, W. Quaternary rare earth transition metal arsenide oxides RTAsO ( $\mathrm{T}=\mathrm{Fe}, \mathrm{Ru}, \mathrm{Co}$ ) with ZrCuSiAs type structure. J. Alloys Compd. 302, 70-74 (2000).

33 Kamihara, Y., Watanabe, T., Hirano, M. \& Hosono, H. Iron-based layered superconductor $\mathrm{La}[01-\mathrm{xFx}] \mathrm{FeAs}(\mathrm{x}=0.05-0.12)$ with $\mathrm{Tc}=26 \mathrm{~K}$. J. Am. Chem. Soc. 130, 3296-3297 (2008).

34 Ohta, H., Kim, S., Mune, Y., Mizoguchi, T., Nomura, K., Ohta, S., Nomura, T., Nakanishi, Y., Ikuhara, Y., Hirano, M., Hosono, H. \& Koumoto, K. Giant thermoelectric Seebeck coefficient of two-dimensional electron gas in SrTiO3. Nature Mater. 6, 129-134 (2007).

35 Yamamoto, M., Ohta, H. \& Koumoto, K. Thermoelectric phase diagram in a CaTiO3SrTi03-BaTiO3 system. Appl. Phys. Lett. 90, 072101 (2007).

36 Zhao, L. D., Zhang, B. P., Liu, W. S. \& Li, J. F. Effect of mixed grain sizes on thermoelectric performance of Bi2Te3 compound. J. Appl. Phys. 105, 023704 (2009).
37 Ravich, I. I., Efimova, B. A. \& Smirnov, I. A. Semiconducting Lead Chalcogenides (Plenum, New York, NY, USA, 1970).

38 Fitsul, I. V. Heavily Doped Semiconductors (Plenum, New York, NY, USA, 1969).

39 Kumar, G. S., Prasad, G. \& Pohl, R. O. Experimental determinations of the Lorenz number. J. Mater. Sci. 8, 4261-4272 (1993).

40 Wan, C. L., Pan, W., Xu, Q., Qin, Y. X., Wang, J. D., Qu, Z. X. \& Fang, M. H. Effect of point defects on the thermal transport properties of (LaxGd1-x)2Zr207: experiment and theoretical model. Phys. Rev. B 74, 144109 (2006).

41 Callayway, J. \& von Baeyer, H. C. Effect of point imperfections on lattice thermal conductivity. Phys. Rev. 120, 1149-1154 (1960)

42 Liu, W. S., Zhang, B. P., Li, J. F., Zhang, H. L. \& Zhao, L. D. Enhanced thermoelectric properties in CoSb3-xTex alloys prepared by mechanical alloying and spark plasma sintering. J. Appl. Phys. 102, 103717 (2007).

43 Koumoto, K., Funahashi, R., Guilmeau, E., Miyazaki, Y., Weidenkaff, A., Wang, Y. \& Wan, C. Thermoelectric ceramics for energy harvesting. J. Am. Ceram. Soc. 96, 1-23 (2013).

44 Roufosse, M. C. \& Klemens, P. G. Thermal conductivity of complex dielectric crystals. Phys. Rev. B 7, 5379-5386 (1973).

45 Wan, C. L., Qu, Z. X., He, Y., Luan, D. \& Pan, W. Ultralow thermal conductivity in highly anion-defective aluminates. Phys. Rev. Lett. 101, 085901 (2008).

46 loffe, A. F. Physics of Semiconductors (Infosearch, London, UK, 1958).

47 Sanditov, D. S. \& Belomestnykh, V. N. Relation between the parameters of the elasticity theory and averaged bulk modulus of solids. Tech. Phys. 56, 1619-1623 (2011).

48 Morelli, D. T. \& Slack, G. A. In: High Thermal Conductivity Materials (eds. Shinde, S. \& Goela, J.) Ch. 2, 37-64 (Springer, New York, NY, USA, 2005).

49 Bozin, E. S., Malliakas, C. D., Souvatzis, P., Proffen, T., Spaldin, N. A., Kanatzidis, M G. \& Billinge, S. J. L. Entropically stabilized local dipole formation in lead chalcogenides. Science 330, 1660-1663 (2010).

50 Skoug, E. J., Cain, J. D. \& Morelli, D. T. Structural effects on the lattice thermal conductivity of ternary antimony- and bismuth-containing chalcogenide semiconductors. Appl. Phys. Lett. 96, 181905 (2010).

51 Huang, B. L. \& Kaviany, M. Structural metrics of high-temperature lattice conductivity. J. Appl. Phys. 100, 123507 (2006)

52 Payne, D. J., Egdell, R. G. Walsh, A., Watson, G. W., Guo, J., Glans, P. A., Learmonth, T. \& Smith, K. E. Electronic origins of structural distortions in post-transition metal oxides: experimental and theoretical evidence for a revision of the lone pair model. Phys. Rev. Lett. 96, 157403 (2006).

53 Venkatasubramanian, R., Siivola, E., Colpitts, T. \& O'Quinn, B. Thin-film thermoelectric devices with high room-temperature figures of merit. Nature 413, 597-602 (2001).

54 Clarke, D. R. Materials selection guidelines for low thermal conductivity thermal barrier coatings. Surf. Coat. Technol. 163, 67-74 (2003).

\footnotetext{
(c) (i) () $\ominus$ This work is licensed under a Creative Commons Attribution-NonCommercial-NoDerivs 3.0 Unported License. To view a copy of this license, visit http://creativecommons. org/licenses/by-nc-nd/3.0/
}

Supplementary Information accompanies the paper on the NPG Asia Materials website (http://www.nature.com/am) 